Article

\title{
Port Digitalization with Open Data: Challenges, Opportunities, and Integrations
}

\author{
Tommi Inkinen ${ }^{1} * * \mathbb{C}$, Reima Helminen ${ }^{1}$ and Janne Saarikoski ${ }^{2}$ \\ 1 Centre for Maritime Studies, Brahea Centre, University of Turku, FI-20014 Turun yliopisto, Finland; \\ reima.helminen@utu.fi \\ 2 Kotka Maritime Research Association, Keskuskatu 10, 48100 Kotka, Finland; janne.saarikoski@merikotka.fi \\ * Correspondence: tommi.inkinen@utu.fi; Tel.: +358-50-313-0689
}

Received: 10 April 2019; Accepted: 13 May 2019; Published: 16 May 2019

check for updates

\begin{abstract}
Digitalization is frequently addressed in recent economic and social scientific literature. This paper applies a distinction to digital data (raw data) and digital technologies (including both software platforms and hardware solutions). The open data is defined as follows: it is publicly available and non-chargeable data (information content) that is machine readable. Open data enables software and application development for external partners and users. A common feature in open-data applications is location-based identification (e.g., real-time traffic monitoring). These include spatial map visualizations, and monitoring of traffic and modes of transport. This visualized information provides additional support for data-based decision-making and management as these study results indicate. This information is valuable particularly in the decisions concerning unconventional and sudden events. This research indicates that the most suitable data resources for opening include information related to port transport infrastructure. In terms of temporal monitoring, static road and rail data is currently the most potential alternative for open data in ports. The main reasons are that these data sources are already at least partly published. However, they are not always in open-data formats. Static data is also a grounded starting point because the technical requirements are much less demanding in comparison to real-time data-processing and management
\end{abstract}

Keywords: port management; open data; digitalization; open innovation; transport infrastructure

\section{Introduction}

The maritime sector is an example of a traditional industry where integrations of new digital applications into daily processes and practices have started slowly. This paper focuses on open data and future digitalization potentials in ports that are significant nodes in larger transportation systems. Port connectivity to the respective cities and hinterlands is also a major issue for transport (routing) planning. Effective port-hinterland functionality requires interaction and collaboration between numerous businesses (private sector) and public-sector administrative units (e.g., national customs and transport authorities).

This paper uses three qualitative data sets that are presented in accordance to their content. A form of interview analysis is applied together with selected claim distributions from a port survey targeted at all Finnish ports with international trade. Thus, the main method includes classification of qualitative responses and interpretations. The majority of the results are presented as direct quotes received in the data collection sessions and they are classified into three main categories of arguments. This research indicates that data handling, storing, or development has not been a priority thus far. Additionally, there are information disconnections when transports enter port areas. Based on these considerations, this paper has two main research questions (RQs):

RQ1: To what extent is open data part of the goals, strategies, and daily operations of ports? 
RQ2: What are the future expectations and potentials of open data and digital technologies in the studied ports based on the qualitative data?

The study focuses on Finland, but the results are comparable to all locations that have similar arrangements for port organizations. Additionally, ports around the world have already developed remotely operated cargo-handling methods representing high levels of automation and digital operations management.

\section{Open Data and Innovation in Ports and the Maritime Sector}

Continuous data flow is one of the key aspects in the future digitalization as the real-time transport monitoring and management progresses. For example, traffic data from national government-owned transport infrastructures are, in principle, readily opened, but they are not easily available. They require reliable and interoperable digital solutions, applications, and architectures. In this context, open data may provide flexible alternatives in comparison to traditional closed systems (e.g., mapping applications and interfaces). Open data has also impacted an extensive array of applications ranging from open government services [1-3] to numerous specific fields of science, ranging from e.g., pharmacy [4] to oceanography [5]. A widely studied open-data potential concerns broader concepts of open innovation, business logic, and platforms economics [6-10]. Open data is one of the crowd-sourcing enablers and particularly significant to start-up software companies.

Open data, open innovation, and digitalization are often treated together. A practical way to see open data is that is an enabler of innovations based on mindset of "openness" [11-13]. Hossain et al. [14], de Paulo et al. [15], and Zhang et al. [16] have conducted systematic literature reviews focusing on open innovation and open data. These literature reviews show that the majority of open-innovation literature is conducted in the fields of business studies and innovation systems whereas open data is commonly associated with administrative, governmental, and technical sciences $[17,18]$.

The academic research of ports has steadily moved from logistical network analyses and models towards multidisciplinary research with applications, e.g., in transport geography [19]. This is understandable as a majority of port research has traditionally focused on location analyses, network optimization, volumes, and transport profiles (in comparison to other ports), and specialization in cargo-handling (e.g., [20]). Intermodal transport chains have also attracted a significant amount of research interest (e.g., [21]). Earlier studies pinpoint the importance of networks and knowledge transfer. This is relevant as ports are communities and thus they represent an array of networks operating on different scales: from global connectivity to local everyday communications. In practice, an integrative factor is that each member of the port community (i.e., organizations located within the port vicinity) possesses information (data) that is beneficial to others. This creates motivation for opening the data at least to an extent in which core information and competition advantage is not in jeopardy. The operational interlinkage in data management is therefore tightly embedded into the level of collaboration intensity and depth. The current development mindset in ports focuses on general improvement of data sharing, storing, and transfer (in the case of big data, see [22]).

Open data is often associated with the public sector as indicated by Chatfield and Reddick [23] who have conducted a longitudinal analysis of local government services in Australia. Similarly, Inkinen $[24,25]$ presented an overview of municipal e-government properties with respect to online websites of Finnish local governments and the best digitalization practices awarded by the Finnish National Government. These experiences show backgrounds for successful open (or public-sector) digitalization efforts that, at least in principle, also apply to open data and innovation. The public sector plays a significant role, particularly in the cases of ports, as the majority of them are owned by municipalities in Finland. Each port develops and promotes digitalization on the basis of their internal needs. Therefore, the digitalization effort, in which open-data progression belongs, is not in the hands of a single actor, and thus requires frictionless collaboration between organizations of the port community. The coordination responsibility of open-data projects could be organized around these port communities. 
This requires a change from providing only physical infrastructures in material transportation towards digitalized management of logistics data that could then be opened to a desired extent.

Data-transfer automation benefits port community members through easier means of acquiring data. The automation would also ensure that the data is uploaded or entered into the system only once reassuring that it is similar in all cases (eliminating conflicting data entries). Finnish port authorities and organizations are mainly small- or medium-sized enterprises (SMEs) causing limited resources in data management and development. This also hinders digitalization that should provide fast and almost instant visible benefits, compensating the efforts for system development. Therefore, port communities apply a vast number of different hardware and software systems from different time periods and with different maintenance requirements. Interoperability of data transfer is regrettably often non-existent or requires extensive amounts of work. This leads to a limited level of data sharing due to technical difficulties.

There are several ways to classify diverse data sources and sets. In this paper, the first criterion is the level of openness. Public data refers to data to which all have unlimited access and unlimited user rights. Open data refers to data to which all have permission to reuse the data but only according to the copyright definitions. Closed data is usable only with permission. Dahlander \& Gann [26] discussed the level and categorization of openness in innovation production. Their study indicated that the complexity and diversity related to degrees of openness and the levels that lay between extremities (fully open vs. fully closed) depend on the applied criteria. This issue is relevant for the open data as it may be considered to be a source or resource for an innovation-open data-open innovation. Openness is also a question of intellectual property rights (IPRs). This means that the difference between the public data and open data is in the user agreements set by the copyright holder. User agreements are commonly stated in metadata or at the data retrieval source (data storages, catalogues, and other sources). Restricted (or closed) data requires permissions and involves definitions of the use rights set by the copyright agreement.

The open-data concept intertwines conceptual definitions of data and information together. Thus, data is either a classified or non-classified set of symbols that have content values to separate each value from each other. Information, on the other hand, may be a single entity that entails information (e.g., a picture) but the value construction has been differentiated either by the user or algorithm to define the content of the information. Pictures and PDFs, for example, are open information but not automatically open data unless their properties are separately classified and available. In practice, structural JSON, XML, or CSV formats are typical for automated and ready-to-process forms of data referring here to "open data". Other properties common to open data also include that it is freely, legally, and technically reusable without (financial) charges or costs.

Open data is most commonly delivered through direct uploads or through programming interfaces. API (Application Programming Interface) is an example of an interface allowing means to access and reuse data in specific operating systems. This involves system interoperability where different programs are able to query and exchange data. Thus, they are program interfaces for machine-based communication. Open data is either static or dynamic. Static data is by definition stable and lasting. Static data requires updating by the data provider. It can be handmade or automated (e.g., certain intervals). The updating frequency is often long (months or years, see studies reviewed in [16]). In the case of ports, the updating usually takes place after renovations, maintenance, or alteration works. In addition, changes in port infrastructure require updating and new observations. Dynamic data, on the other hand, is constantly changing without predefined intervals. The updating requires automation in the data-processing and the data monitoring (collection systems) may update the database whenever new data is observed and stored. The most common examples are dynamic ship, vehicle, and transport location data.

In the case of waterborne transport, dynamic data is generated in professional maritime information systems managed by Traffic Management Finland (a national government-owned company since 2019), including: 
- Warnings: operative security deviances and other active sea warnings

- Vessel arrival/departure times (Portnet system in the case of Finland)

- Vessel location data (Automatic Identification System (AIS) system)

- Vessel and port description data (metadata)

Maritime traffic and port operations require constant information on weather and environment. The Finnish Meteorological Institute (FMI) provides open data on these variables. In the case of weather conditions there are three main classes of open data: real-time, time-series, and forecasts. The ports of Finland are located on the shores of the Baltic Sea where winter seafaring constitutes a significant part of the annual transport cycle. In this regard, there are specific data sources for winter conditions and the currently available open data includes vessel information on location, icing grade, destination, and schedule. The data also involves ports themselves with their static location data and dynamic restriction data (e.g., congestion).

The most important and significant data for ports and vessels is the real-time location data both for port operation planning as well as ship navigation. AIS is the current standard for obtaining this data. It is based on communication equipment installed in ships and the vessels broadcast their location information via specific radio frequencies reserved for AIS communication. The system is global and compulsory for professional maritime traffic (class A device) and optional for leisure and smaller boats/vessels. An A-class device broadcasts location data automatically in 2 to $10 \mathrm{~s}$ intervals. This data is openly available for all relevant parties requiring the data.

\section{Study Design, Data, and Methods}

This study is an outlook to stakeholder views on digitalization and open data. Therefore, the study applies a methodological mix including data from four main sources: (1) interviews; (2) field observations at ports; (3) workshops for port communities; and (4) online survey for port authorities. These data sources are treated in accordance with the European Commission's [27] analysis tool "Digital Transformation Scoreboard" (DTS) that presents seven key technologies for digitalization:

(1) The analysis of big data.

(2) Automation and robotics

(3) Cyber-security

(4) Internet of Things (IoT) and sensor networks

(5) Cloud computing and services

(6) Mobile services

(7) Social media

This classification is applied in the empirical section as the basis for survey questions addressing future prospects of open data. Similarly, different technological solutions have been divided into value-adding networks-these have been applied in the qualitative workshops (group discussions). These networks have also been considered with respective future challenges and needs, e.g., in the case of open innovation, see [28]. This is further connected to the role of human work (employment) and to the roles of labor unions. In particular, stevedoring and loading functionalities are still labor-driven but automation has a great potential to modernize these segments within the industry.

Interviews were conducted between September-November 2017 and their main purpose was to collect ground information that would help other data collection events later. The interviews were focused on two pilot ports that were selected on the basis of their size (both of them are significant international trade ports in Finland) and transport profile. The ports are HaminaKotka (the largest container port in Finland); and the port of Turku (significant passenger and cargo transport hub in the South-West Finland). Both ports are municipality owned and therefore city authorities overseeing them were included from the following organizations: technical services of the city of Kotka; city development of the city of Hamina; strategy and development of the city of Turku (2 interviews); and 
the Association of Finnish Local and Regional Authorities. In total seven persons representing these organizations were interviewed. City authorities also expressed their interest towards open data and the current condition of data availability and management in reference ports. All interviews were personal one-to-one interviews with a loose structure enabling respondents to present their own ideas and comments on the topic.

In the data collection the interviews were followed by field observations at the port areas. The purpose of the site visits was to gain understanding of the physical structures and functionalities through which open data could be obtained from. The site visits included also significant amount of site related informal talks and discussions concerning the port conditions and their readiness to incorporate digitalization into the daily port operations. This tacit knowledge aided the researchers to understand the challenges embedded into the physical structures and locations as well as work culture and practice through which port communities operate. These visits took place between October and December 2017 following right after the interviews.

The third data collection form included workshops that may be considered here as semi-structured group interviews (brainstorming). Two separate meetings were arranged in March 2018 with the same topic "Problem solving in ports with digitalization and data". Overall there were 52 persons (27 in the meeting held in the city of Turku and 25 in the city of Kotka) participating the workshops. Registered attendants were representing all relevant stakeholder groups. These include port operators, city representatives, stevedoring, handling, shipping companies, ice breaking, towing, piloting, maritime industries, software companies, employer and labor organizations, and research institutions. In addition, also key national government representatives were present from the Ministries of Transport and Communications, and Finnish Customs.

The workshops were thematically pre-organized into four stages. Participants were divided into four smaller groups according to their own interests, but all groups circulated each thematic stage. This was necessary to ensure and enhance quality and diversity of stakeholder views. Workshop data collection often suffers from too narrow and one-sided views if participants work only in their specific thematic areas. The thematic areas were defined as follows: (1) Operative efficiency, flexibility, and operations reliability; (2) Information distribution, availability, and interoperability; (3) Port safety, security, and the environment; and (4) Transportation flows, functionality (guidance and management), and infrastructure (land areas, waterways, piers, buildings, loading areas, daily operations). The workshop argumentation was recorded, and the qualitative data is incorporated with the data obtained from the interviews and field observations.

The final (fourth) form of data collection was a survey targeted at all Finnish seaports with international trade (either imports or exports) [29]. The survey focused on infrastructure data as it was defined (in interviews and workshops) to be the most potent thematic area for open data. The survey was conducted between May and June in 2018. Structured questions included also open text alternatives for those respondents wishing to clarify their responses or did not find a suitable selection in fixed response alternatives. The survey was conducted online by using Webropol platform. Total sample size is 22 that covers $98.6 \%$ of all Finnish foreign trade in 2017. Out of those 22 ports 19 responded covering $97.3 \%$ of foreign seaborne trade in tons respectively [30]. Each port could decide within their organizations the best possible respondent for the survey. Approximately one third of the respondents were CEOs of ports, and the rest included a diverse group of higher executives from technical departments, economic offices, and transport managers. The collected data is representative and gives a grounded view of the top management of ports towards open data and digitalization.

\section{Results}

The results section is divided into two parts. The first part presents key results obtained from the survey (Table 1 and Figure 1). Second, the combined results of the qualitative materials (interviews, field observation, and workshops) are presented collectively in Tables 2 and 3. All statements are on a 
five-step Likert-scale with a sixth alternative of "I do not know". All claims follow the logic in which 1 equals the least and 5 the best option.

Table 1. Distributions of survey responses (in percentages) to the three key questions (claims).

\begin{tabular}{|c|c|c|c|c|c|c|}
\hline $\begin{array}{c}\text { Claim (1 = The Lowest/Weakest/None; } \\
5 \text { = The Best/Greatest/Most) }\end{array}$ & 1 & 2 & 3 & 4 & 5 & $\begin{array}{l}\text { Do Not } \\
\text { Know }\end{array}$ \\
\hline $\begin{array}{l}\text { How much does your port have information } \\
\text { needs concerning digitalization? }\end{array}$ & $0 \%$ & $10.5 \%$ & $10.5 \%$ & $47.4 \%$ & $31.6 \%$ & $0.0 \%$ \\
\hline $\begin{array}{l}\text { What is the level of digitalization in your } \\
\text { port in comparison to other Finnish ports? }\end{array}$ & $5.3 \%$ & $26.3 \%$ & $36.8 \%$ & $26.3 \%$ & $0.0 \%$ & $5.3 \%$ \\
\hline $\begin{array}{l}\text { What is the significance of } \\
\text { digitalization in your port strategy? }\end{array}$ & $0 \%$ & $11 \%$ & $26 \%$ & $37 \%$ & $26 \%$ & $0 \%$ \\
\hline
\end{tabular}

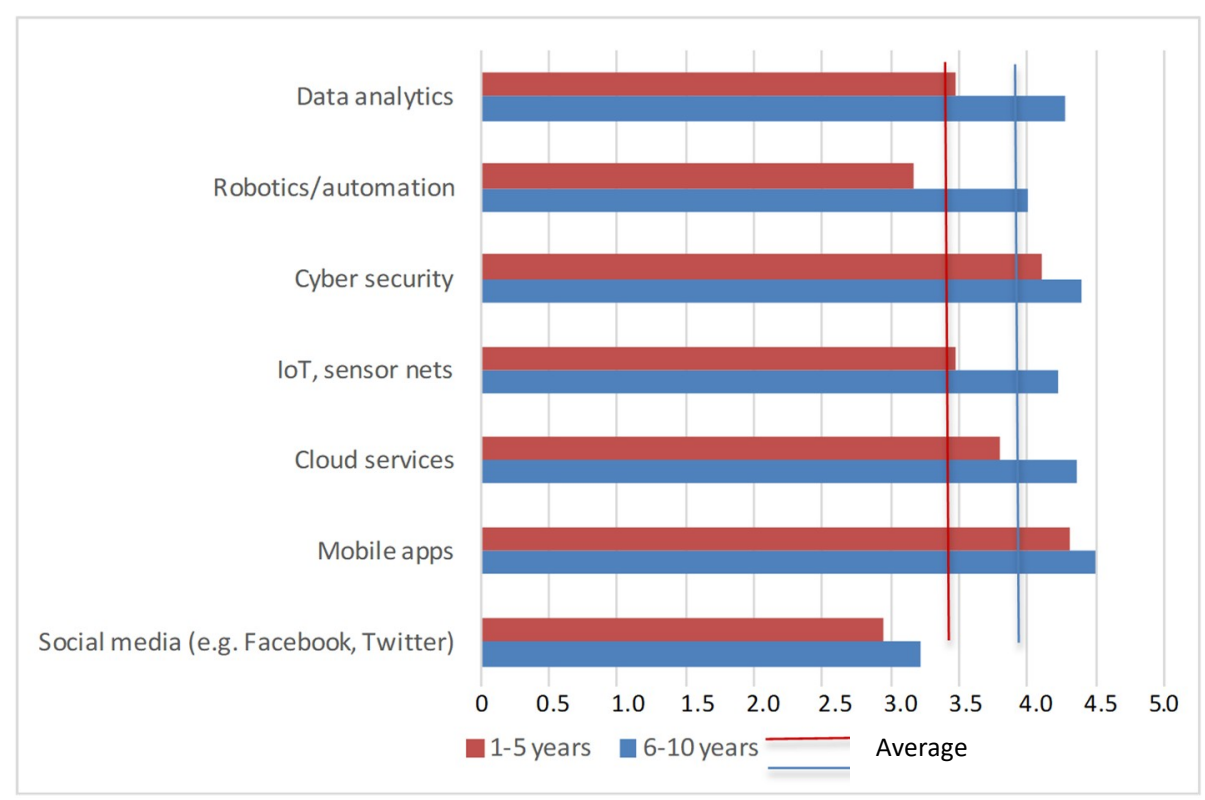

Figure 1. Port considerations of key technologies and their significance $(0=$ no importance; $5=$ the highest importance) in two time spans (1 to 5 years) and (6 to 10 years).

Table 1 gives answers to RQ1. Responses indicate that ports consider them realistically in comparison to others. The distribution of answers follows a neat standard distribution curve. Similarly, ports consider that they do have significant information needs concerning digitalization that also has more significant place in port strategies than other empirical evidence would suggest. This is a common feature in strategic management resulting into higher scores on goal setting than is the current reality. The respondents had problems in identifying operational systems that are implemented in ports. The survey question was formulated as "what digital solutions are in use in your port?" Only 13 of 19 ports answered to this open question. A fourth of respondents simply stated e.g., that "there are several non-communicating systems in use" but did not define the actual systems. Majority of the responses raised digitalized port operations management system and traffic monitoring (gate and camera systems). The fragmentation of responses and general statements indicate that it is likely that majority of the ports have not conducted a comprehensive inventory of the applied digital solutions. 
Table 2. Digital solutions identified by the studied ports (numbers in brackets refer to the main category of arguments presented after Table 3).

\begin{tabular}{|c|c|}
\hline Theme & Decided and Planned Solutions for the Theme \\
\hline $\begin{array}{l}\text { Road, rail and waterborne } \\
\text { traffic channels: }\end{array}$ & $\begin{array}{ll}\text { - } & \text { Intelligent guidance of traffic and parking }(1,2,3) \\
\text { - } & \text { Intersection safety }(3) \\
\text { - } & \text { Rail monitoring with sensors }(2) \\
\text { - } & \text { Operation information of security devices on water areas }(2,3) \\
\text { - } & \text { Depth data }(2) \\
\text { Port's weather station }(1,2)\end{array}$ \\
\hline Buildings and areas: & $\begin{array}{ll}\text { - } & \text { Conforming map coordinate system use in different parts of a port }(2) \\
\text { - } & \text { Resource dividing between/with user segments }(1) \\
\text { - } & \text { Infrastructure service dividing between/with organizations (maintenance, winter conditioning) }(1,2) \\
\text { - } & \text { Technical data portal in a port }(2) \\
\text { - } & \text { Vessel automated mounting (automooring) }(1,2) \\
\text { - } & \text { Automated vehicle scaling system }(2)\end{array}$ \\
\hline Technical networks: & $\begin{array}{ll}- & \text { Anticipating maintenance with sensor data (2) } \\
\text { - } & \text { Intelligent lighting guidance (2) } \\
\text { - } & \text { Intelligent camera and image recognition systems (2) } \\
\text { WLAN for port customers and organizations (2) }\end{array}$ \\
\hline Port management (whole): & $\begin{array}{ll}\text { - } & \text { Enhanced data and information distribution: Port snapshot system (2) } \\
\text { - } & \text { Interaction improvement (1) } \\
\text { - } & \text { Mobile applications on defects reporting (2) } \\
\text { - } & \text { Close call and deviation messaging information distribution to all stakeholders }(1,2) \\
\text { - } & \text { Hazardous situation informing for port community employees (3) } \\
\text { - } & \text { Port related industries integration with port operations (1) }\end{array}$ \\
\hline Dynamic traffic data: & $\begin{array}{l}\text { - } \quad \text { Mobile application for travelers, enhanced travel experience (2) } \\
\text { - } \quad \text { Tugboat visibility (physical) to ports (1) } \\
\text { - } \quad \text { Information delivery of traffic conditions/obstacles on the paths leading to ports (2) }\end{array}$ \\
\hline
\end{tabular}


Table 3. Port community observations focusing on thematic areas (numbers in brackets refer to the main category of arguments presented after Table 3).

\begin{tabular}{|c|c|}
\hline Subject area & Workshop (Collective Interviews) Observations: \\
\hline $\begin{array}{l}\text { Collaboration and data } \\
\text { sharing within } \\
\text { port community: }\end{array}$ & $\begin{array}{l}\text { - } \quad \text { "Numerous technologies applied in data sharing" }(2) \\
\text { - } \quad \text { "Too much email and telephone communications" }(1,2) \\
\text { - } \quad \text { "A common information systems that are not interoperable" }(2) \\
\text { - "Schedules are unreliable and a lack of information" }(1,2) \\
\text { - "Problems in shift changes are stopping processes" }(1) \\
\text { - "Time and money are wasted in pauses/waiting" }(1) \\
\text { - "Stevedoring and ship timetables are in mismatch" }(1,2) \\
\text { - "Attitude problem: no willingness to exchange data/information" (1) } \\
\text { - "Keeping data/information to oneself in expectation of gains" (1) } \\
\text { - "A lack of information of responsibilities - not my business/task" (1) }\end{array}$ \\
\hline Port state of affairs: & $\begin{array}{l}\text { - "A common vision is missing. Timings, equipment condition (vessels, cargo-handling, several personnel mismatch)" (1) } \\
\text { - "Real-time guidance in port logistics is missing" (2) } \\
\text { - "Real-time data is missing" (2) } \\
\text { - "Process measuring is inadequate" (2) } \\
\text { - "No real-time measurement for efficiency" (2) } \\
\text { - "No transparency because measures and indicators are missing" }(1,2) \\
\text { - "Historical data should not strain users" (2) } \\
\text { - "Announcements of subcontractor activities should be enhanced" (1) }\end{array}$ \\
\hline $\begin{array}{l}\text { Port infrastructure } \\
\text { and related data: }\end{array}$ & $\begin{array}{l}\text { - } \quad \text { "Operators do not always know specifications e.g., pier carrying capacity" }(1,2) \\
\text { - } \quad \text { "Piers should be specified in accordance to their capabilities" }(1,2) \\
\text { - } \quad \text { "Timely maps of pier structures and cargo lifts are needed" }(2) \\
\text { - } \quad \text { "Mutomation is poorly used" }(1,2) \\
\text { - } \quad \text { "Maintenance requests and feedback are not functioning properly" }(2) \\
\text { - } \quad \text { "Infrastructure responsibilities are not clearly defined causing problems" }(1,2) \\
\text { - } \quad \text { "Infrastructure drawings are catalogued in various ways causing problems in retrieval and consistency" (2) } \\
\text { - } \quad \text { "Inventories concerning older infrastructure and documentation is resource consuming" (2) } \\
\text { - } \quad \text { "Cities are putting pressure on port spatial planning (requiring space for other uses)" (3) }\end{array}$ \\
\hline
\end{tabular}


Table 3. Cont

\begin{tabular}{|c|c|}
\hline Subject area & Workshop (Collective Interviews) Observations: \\
\hline $\begin{array}{l}\text { Overland traffic to and out of } \\
\text { the port } \\
\text { (road and rail connections): }\end{array}$ & $\begin{array}{l}\text { - "Advance notices of arrival are not always available causing problems in rites of passage" }(1,2) \\
\text { - "Drivers (truck) do not retrieve pre-information of port systems beforehand" }(1) \\
\text { - "Poor guidance for passenger car traffic" }(1) \\
\text { - "Congestion of the port leading routes" }(1,3) \\
\text { - "Ground speed limits are disobeyed" }(3) \\
\text { - "Ports have several dangerous rail and road crossings" }(1,3) \\
\text { - "Praffic management of areas outside ports is uncontrollable" }(1,3) \\
\text { - "Ports are not considered/taken into an account in urban planning" }(1)\end{array}$ \\
\hline $\begin{array}{l}\text { Waterborne traffic } \\
\text { in port vicinity: }\end{array}$ & $\begin{array}{l}\text { - "Pilotage does not receive real-time weather data from current systems" (2) } \\
\text { - "Wind data are fragmented (The Finnish Transport Infrastructure Agency, Institute of Meteorology, Ports) (2) } \\
\text { - "Information sources and data reliability are varying" (2) } \\
\text { - "Where does the responsibility of a port end?" (1) }\end{array}$ \\
\hline Safety and security: & $\begin{array}{l}\text { - "Passage control and security monitoring are nominal" }(1,3) \\
\text { - "Rites of passage are not always correctly limited" }(1) \\
\text { - } \quad \text { "Too easy access" }(1) \\
\text { - "Moving in port areas is blurred as the guidance is missing" }(3) \\
\text { - "Port manual exists but not in digitalized form" }(2) \\
\text { - "Whermation distribution in deviant/hazardous situations concerning the whole port area" }(3,2,1) \\
\text { - "Real-time data concerning hazardous materials is missing" } \\
\text { - "Chemicals pose a great risk" }(3) \\
\text { - "Is there location data concerning hazardous materials?" }(3,2)\end{array}$ \\
\hline Environment: & $\begin{array}{l}\text { - "Environmental stress caused by vessels and cargo" (3) } \\
\text { - "Sloppy handling of fertilizers in uploading: fertilizers may end up in sea" (3) } \\
\text { - "Authorities lack knowledge of environmental issues in ports" (3) } \\
\text { - "Legal permits for environmental licenses (9 months) take too long for customers" (3) } \\
\text { - "Waste handling points are too few and their condition data is limited" }(3,2)\end{array}$ \\
\hline
\end{tabular}


The respondents recognized several development targets for digitalization (Table 3). The broad themes included better management tools for port infrastructure and maintenance. Also, the real-time location information of machinery (e.g., movable lifts and cranes) would increase reliability and efficiency. Remote control of infrastructure (machinery, heating, and lightning) was also considered to be a priority. The final significant broad development area was defined to include real-time data management on weather conditions, cargo tracking, and traffic monitoring in general. A few responses raised an issue of forecasting of wave heights, wind directions, and correlations of ETA (Estimated Time of Arrival) and observed arrival times in relation to wind conditions. Three respondents went even further and considered that ports will transform towards more operative direction and service platforms, and that digital data and information will have a crucial role in the transformation from a cargo node towards data communications node. Digitalization was considered to be mainly a positive phenomenon, but the main challenges were considered to be separate from it. These include (relatively) small cargo flows due to the market sizes and distribution networks from the Finnish ports. Ports have obtained quite slow digitalization tempo and majority of the respondents stated that they have adopted observer's role in the development of digitalization and are preparing to take the necessary steps but are not in the forefront of the development.

The survey was designed to indicate future conceptions of the most potential technologies in ports. For this purpose, Figure 1 presents two timeframes (till 5 years; and till 10 years) with predefined technology areas. The ports were asked to consider their significance in accordance with the two time options. The predefined technology categories are based on the DTS [27] that was originally designated to other industrial sectors (technology, health, and automobile) than maritime (including ports). However, based on the responses it proved to be applicable also in this industry.

The survey highlighted the importance of mobile services and data security. They were considered to be the most important development areas in the upcoming years. Interestingly, the impact of social media and its significance was considered to be least important. Four ports reported in the open commentaries that digitalization has been included into the ongoing strategy processes. There is also a limited number of ongoing digitalization projects done with the European Union funding. The result indicates that digitalization is progressing in ports either 1) as a strategic choice or 2) through individual projects, which are tackling single problems, development needs, and system upgrades separately.

Larger ports considered that they are ahead of other ports. However, none of the ports considered themselves to be significantly ahead of the others (Table 1, Option 5). There is clear consensus among the ports that all defined technologies in Figure 1 will increase their significance in daily operations in the near and mid-future scenarios. The longer the scope the more significant the technological change is considered to be. Results also indicate that mobile services (applications) and cyber-security are estimated to be the most significant technology fields. However, the observed differences are small, and they are not statistically significant except social media that gained the lowest importance (t-statistic sig. $<0.001$ ). It is likely that the impact of social media will be limited to external communications (marketing, information distribution) and will have a modest role in internal (actual work related) port development.

The following considerations are raised in order to respond to RQ2: Larger ports (in transport tonnages and in monetary values) are those that appreciate and act the most in terms of digitalization. They also perceive the importance of the future knowledge the highest. Table 2 indicates the ground level approach of ports to tackle with digitalization. Practically all efforts for the future solutions are based on infrastructure (buildings, routes, and technical networks) or data properties. This causes that majority of the arguments are on the category 2 (see below). There is a contrast if problems and challenges are considered. Table 3 responses have more balanced division with the constructed three argument categories that are hindering the progress of digitalization in ports (their supportive arguments are marked in Tables with respective numbers):

(1) Segmentation and silos of operations that are not communicating well enough-traditional working culture (40 arguments in Tables 2 and 3); 
(2) Multitude of data sources and the lack of interoperability-technological fragmentation (51 arguments);

(3) Legislation and regulation of security and environment-authorities and responsibilities (22 arguments).

The first point not only concern technological issues but mainly works traditions and trajectories of port working cultures. The argued "lack of common vision" may be considered to be one manifestation of the problem easily created in large subcontracting and operator networks such as ports. The creation of common digital platforms in these types of organizational environments is a difficult task. The second point is a traditional obstacle in large information system development and is still very much present in ports. This point highlights the slow change phase of ports. This second point is also connected to the first one as it may be seen as a foundation for segmentation in port operations. Large subcontracting networks cause these information-flow deficits easily. The third and final point indicates arguments concerning legislation and regulation. Legislation has been slow in responding to digitalization challenges as well as changes in environmental requirements driven by the International Maritime Organization (IMO) on vessels. These new requirements and regulations also impact ports as they provide e.g., waste facilities and handling.

Overall, the responses follow familiar pattern in their considerations of required future knowledge of digitalization. The lowest response distributions were received from small- and medium-sized ports focusing on limited cargo types. 12 respondents wrote clarifications to the open cells in the questionnaire. The following points were raised:

- A need for better (already existing) data use from dispersed sources that is not easily accessible. This leads to the combination and data management challenge.

- A need for better communications in data use and data storage identification between different actors within the supply chain.

- A need for individually identified technologies including e.g., block-chain, Internet of Things, data-transfer protocols, interoperability solutions, real-time weather data, open traffic data, location-based services, and identification technologies.

- A need for enhanced development of back-office data systems including financial monitoring and reporting.

Infrastructure data in ports often suffers from uncertainties related to data storing. This means that data is often bound to individuals with personal interest to store the data. Thus, there are no systematized processes for data storing. This evidently leads into a situation, in which data storages are scattered and inconsistently maintained. It is exceedingly rare that these resources would be available online (e.g., intranets). Variations manifest themselves also through inconsistent data formats and maintenance. Interoperability is still a great challenge even though it has been identified as one of the major hinderances of digitalization (e.g., [25]). Even machine readability is too often missing as numerous files have been stored as PDFs or pictures (raster format representing e.g., maps). The information thus exists but the modification possibilities have been lost. In addition, several infrastructure data sources are owned by third parties (e.g., water companies) and their availability is limited to other port community members. The mixture is further complicated by the great number of different Enterprise Resource Planning (ERP) systems that do not communicate well with each other. Sometimes "ERP" system is an Excel or Access file in port operating firm. In practice, data systems are updated on the need basis in accordance to each separate maintenance and upgrading work. This situation is far from optimal and explicates the extensiveness of barriers in digitalization in ports.

\section{Discussion}

\subsection{Current Situation of Open Data in Ports}

Based on the interviews, digitalization is not clearly visible, considered, or included in the strategies of ports. This explains the current situation that none of the ports have a person solely 
responsible or focusing on digital service development. Instead, digitalization progression is based on individual motivations and backgrounds of the people who are working with issues and topics where digitalization could be advanced. There are single projects tackling with digitalization from the perspective of customer end-services (e.g., applications of digital forms) or data transfer within a supply chain. An interesting result is that cities that own the ports are more active in the development of digital services, if compared to port organizations, particularly in the context of open data, e.g., open data in cities, the case of Helsinki [31].

Data sharing in ports requires trust and openness. There are increasing pressures that also concern ports in the increasing of transparency and thus open-data solutions. They are needed in order to improve traffic flow capacity and functionality. Ports have traditionally worked mainly according to the closed data principle and with a collection of peer-to-peer contracts. A midway solution here might be a consideration of creating data resources that are open to port community members but are restricted to external parties. The study also indicated a basic problem in advanced data management that even open data, big data, and other popular terms are widely used, different stakeholders and people perceive and understand these concepts (terminology) differently. There are also differences in the ways how transitional terminology is understood meaning that solutions that are not fully open nor fully closed are defined in each particular development action within the frame of that action. At least the distinction between "fully open data" and "partially open data" is needed to be considered in the future manuals and guides prepared for port communities.

Open data provides a way for organizations, employees, and other private persons to update their data storages and knowledge needs also [32]. Data combining enables more detailed analyses and decision support base. Important stakeholder groups for the beneficial use of open data are start-up companies and software developers. The current applications applying open data in transport are most often visualization tools or cartographic interfaces for real-time traffic monitoring. They are good examples, because they require location technologies data such as GPS (Global Positioning System), transport data (e.g., cargo or passenger) and interface programming capabilities. In the case of maritime sector, AIS data applications (e.g., MarineTraffic) are widely applied in traffic monitoring.

The most suitable data for full opening includes storages related to port transport infrastructure. These also include data on waste management infrastructure. Transport infrastructure as a whole includes data collected on water areas, rail structures, roads, and buildings, structures, and their properties. This data is a basic example of static data that is slowly changing and requires updating only after modifications or changes. Additionally, infrastructure data is already extensively available, and the technical requirements are less demanding in comparison to real-time data (e.g., traffic management data). Infrastructure data is also the easiest data class to open for port authorities since they are in most cases the owners of the infrastructure.

There is a data flow connection (or a breaking) point when the transport unit arrives from publicly owned roads and rail structures to the port vicinity. This change typically breaks the data flow from real-time traffic monitoring. This causes that the most logical path of a development would be to open up the same data that is required outside the port vicinity. There have already been legislative changes on the national level (e.g., in Finland from the beginning of 2018) dictating for example passenger ports to open up significant amounts of previously closed data. However, also these data sets are static and include information on passenger terminal properties, timetables, volumes, and accessibility. This data sources have already been applied by external service developers.

Open data also enables ways for port communities to participate digitalization projects without significant investments. This also allows ports a learning process to obtain benefits from potential service development. A significant development has already been done in the Mobility as a Service (MaaS) model that is strongly developing also in transport of goods and materials. Several countries (including Finland) have created transport policies that require open-data protocols for the development needs of the whole transport system. Ports play a key role in this process as they are significant transport nodes in the whole export-import system. As mentioned, the maritime sector in general is a 
slow changing, traditional industry. Even cataloging existing data storages would start the process towards digitalization in several ports.

\subsection{Future Prospects}

A fundamental principle in open-data provision is that publicly funded operations producing data should always be available, unless there are specific reasons for closing the data. Current legislation is under pressure to keep up with the technological progression. At the moment the governance of open data is based on EU directives, principal decisions and programs. In the case of municipality owned ports (such is the case in Finland) there is a contradiction whether they are regarded as companies (even though fully publicly owned) or organizations with public interest. In the case of private sector, open data will probably remain scarce as the opening process should bring clear economic or process benefits. There is still limited amount of empirical evidence to what extent open data impacts revenues. Publicly owned companies could act as forerunners providing evidence of the pros and cons of open data.

The future demand and supply of transport defines the long-term development plans in ports. Multimodality is an important factor here as the division between rail and road connections set requirements for the facilities and logistics centers (e.g., [33]). Digitalization is tightly intertwined with the increasing environmental regulation and to the overall need for change in transport industry towards sustainability [34,35]. National context matters as there are extensive variations in the ways how port management and ownerships are arranged in different countries. In Finland, the majority of large foreign trade ports are municipality owned companies. There are also privately-owned ports that mainly belong to large export industries and serve their purposes. For example, the largest port in ton volume is privately-owned port located in Sköldvik and it functions as a transport hub for raw oil and oil products.

The digitalization processes taking place in surveyed Finnish ports should be comparable to international benchmarks. However, the ports focusing on digitalization are large international sea hubs and their volumes and resources are exceeding the ones of Finland with a great margin. This causes that straightforward best-practices are not easily implemented in smaller scale. The largest European ports are focusing strongly on data collection (from) and exchange (between) organizations and stakeholders within the supply chain. The results indicated that port communities in Finland are still lacking behind in application and solution development based on open data. The greatest expectations regarding digitalization are focusing on block-chain technologies and potentials that they provide. Another important potential is seen in measurement (e.g., sensors and remote sensing) technologies embedded into infrastructures.

The survey respondents considered that the most prominent technology fields in the near future are mobile services and cyber-security. This is an interesting result as the port communities themselves are cautious to extensively open their data storages. Another key result is that social media itself was considered to be the least significant development area. The port community considers traditional means of communication and trust relations to be the main means of interaction also in the future. On the technical side, the amount of IoT solutions and devices are expected to increase in port communities. The development of IoT in port communities would support overall data management potential and reliability within the whole port system. This requires implementation of future oriented information technologies (e.g., 5G and remote sensing solutions) into the forthcoming investments in physical infrastructure.

Cyber-security will be one of the key development areas in the ports in the near future. This is caused by two main factors: first, the overall digitalization trend and change, and second increasing amount of data related to the transported cargo. These two factors are interlinked and are part of supply-chain management. Transportation documentation also includes valuable agreements and business intelligence vital to the companies conducting international trade with physical products. Cyber-security presents an example of phenomena that is connected to the national supply securities of nations. The service provision and provider contexts give grounds to consider what organizations are providing cloud services and how their intellectual property rights are defined. 
Ports and port communities have a potential to function as living labs for testing new technological solutions in transport. This is enabled by the fact that they are physically closed (fenced) communities where access rights are required. There are international benchmarks, particularly in global mega-ports such as Singapore, where living lab testing has been conducted already in terms of automation and remote controlling of port operations. Finnish technology companies are major players in these developments and thus providing a highly potential platform for the implementation, e.g., in automotive industry [36]. However, the small size of Finnish ports and limited resources hinder these research-based development activities. Finally, in several fields the definition of fully open data appears to be too strict. Bargh et al. [37] have proposed alternatives for coping with open-data definition alternatives and paradigm. Therefore, conceptual work is further needed with respect to specific fields of investigation.

\section{Conclusions}

This study verifies that current mindset in ports towards digitalization does not indicate or refer to a "fully open-data" approach. In the survey, respondents clearly indicated that there are several data types that will never be opened to the public. These data resources concern mainly core business operations, personal information of employees and customers, and security data. It was highlighted that neither privacy nor restricted business information should ever be compromised as a result of open data. However, there are several data contents that may be considered for opening more extensively than currently. The respondents considered that common guidelines and recommendations implemented nationally would be highly beneficial in the opening process. The ports indicated that they lack resources and expertise concerning rapidly changing legislation on data management. In other words, the data is often kept closed as a security measure and "just in case" as there is no full certainty of the legal requirements of what is feasible to open and what is not.

The research indicated that currently there are three main benefits for the use of open data in Finnish ports. First, the open data would enable development work of specific applications needed in daily work. This development work would be done by start-up companies or established programming houses. However, the described limitations still hinder this potential. Second, open data would help the overall coordination of port operations particularly concerning unexpected events or delays in the transport chain. This would also help the port-hinterland integration in terms of arranging e.g., public transport capacity according to real-time needs. Third, open data would enable more transparent and fluid information exchange internally within the port community as well as externally outside the port vicinity.

To achieve the potentials, service design and modeling need user-friendly interface designs. This fundamental in e-service design should be incorporated with clear efficiency of other gains that are easily observable by the end users. The motivation to adopt new technological solutions is founded on reliability and functionality. The user-interface designs are running behind in professional systems compared to consumer-focused e-services (applications in particular). These designs require specific attention, taking into an account the needs and changing conditions that port employees might encounter in their daily work. The data storage and collection does not take place in office environments but on the field operations in the ports, and thus industrial design for professional tools is a necessity. There are highly developed examples of user need-based interfacing from other industries, e.g., forestry and harvesting machinery. These examples could also be learned from in beneficial ways in port contexts.

To conclude, ports are lacking open-data expertise and a strategic vision of implementation. The results also brought up clearly that ports have not actively promoted or published their existing data reserves. Even in cases of the city organizations (owning the ports) the data opening has been, at least partly, passive. The data sources have been opened in accordance with regulative changes from the national level. Machine readability is also a severe problem as e.g., timetables and schedules are often stored in non-machine-readable formats suitable for open data. One information need was defined to be depth data in ports. Another key information need concerns RFID (Radio Frequency 
Identification) technologies and identification systems of transport and personnel. This would help security operations and identification in ports.

Author Contributions: T.I. wrote and designed the paper; R.H. and J.S. designed the approach, collected the data, and conducted the analysis.

Funding: This paper was presented as a keynote speech of SOItmC 2019, and the publishing fee was supported by SOItmC.

Acknowledgments: The authors thank three reviewers for comments improving the paper.

Conflicts of Interest: The authors declare no conflict of interest.

\section{References}

1. Susha, I.; Grönlund, A.; Janssen, M. Driving Factors of Service Innovation using Open Government Data: An Exploratory Study of Entrepreneurs in Two Countries. Inf. Polity 2015, 20, 19-34. [CrossRef]

2. Lin, Y. Open Data and Co-Production of Public Value of BBC Backstage. Int. J. Digit. Telev. 2015, 6, 145-162. [CrossRef]

3. Smith, G.; Sandberg, J. Barriers to Innovating with Open Government Data: Exploring Experiences across Service Phases and User Types. Inf. Polity 2018, 23, 249-265. [CrossRef]

4. Wells, T.N.C.; Willis, P.; Burrows, J.N.; Van Huijsduijnen, R.H. Open Data in Drug Discovery and Development: Lessons from Malaria. Nat. Rev. Drug Discov. 2016, 15, 661-662. [CrossRef]

5. Pattabhi Rama Rao, E.; Udaya Bhaskar, T.V.S.; Venkat Seshu, R.; Srinivasa Rao, N.; Suprit, K.; Geetha, G. Marine Data Services at National Oceanographic Data Centre-India. Data Sci. J. 2018, 17, 11. [CrossRef]

6. Väyrynen, H.; Helander, N.; Vasell, T. Knowledge Management for Open Innovation: Comparing Research Results between SMEs and Large Companies. Int. J. Innov. Manag. 2017, 21, 1740004. [CrossRef]

7. Perkmann, M.; Schildt, H. Open Data Partnerships between Firms and Universities: The Role of Boundary Organizations. Res. Policy 2015, 44, 1133-1143. [CrossRef]

8. Kuhlman, C.; Ramamurthy, K.N.; Sattigeri, P.; Lozano, A.C.; Cao, L.; Reddy, C.; Mojsilovic, A.; Varshney, K.R. How to Foster Innovation: A Data-Driven Approach to Measuring Economic Competitiveness. IBM J. Res. Dev. 2017, 61, 1-12. [CrossRef]

9. Stanko, M.A.; Fisher, G.J.; Bogers, M. Under the Wide Umbrella of Open Innovation. J. Prod. Innov. Manag. 2017, 34, 543-558. [CrossRef]

10. West, J.; Gallagher, S. Challenges of Open Innovation: The Paradox of Firm Investment in Open-Source Software. R D Manag. 2006, 36, 319-331. [CrossRef]

11. Chesbrough, H.W. Open Innovation: The New Imperative for Creating and Profiting from Technology; Harvard Business School Press: Boston, MA, USA, 2003.

12. Chesbrough, H.W. The Era of Open Innovation. MIT Sloan Manag. Rev. 2003, 44, 35-41.

13. Chesbrough, H.; Crowther, A.K. Beyond High Tech: Early Adopters of Open Innovation in Other Industries. R D Manag. 2006, 36, 229-236. [CrossRef]

14. Hossain, M.; Islam, K.M.Z.; Sayeed, M.A.; Kauranen, I. A Comprehensive Review of Open Innovation Literature. J. Sci. Technol. Policy Manag. 2016, 7, 2-25. [CrossRef]

15. de Paulo, A.F.; Carvalho, L.C.; Costa, M.T.G.V.; Lopes, J.E.F.; Galina, S.V.R. Mapping Open Innovation: A Bibliometric Review to Compare Developed and Emerging Countries. Glob. Bus. Rev. 2017, 18, 291-307. [CrossRef]

16. Zhang, Y.; Hua, W.; Yuan, S. Mapping the Scientific Research on Open Data: A Bibliometric Review. Learn. Publ. 2018, 31, 95-106. [CrossRef]

17. Greco, M.; Grimaldi, M.; Cricelli, L. Open Innovation Actions and Innovation Performance: A Literature Review of European Empirical Evidence. Eur. J. Innov. Manag. 2015, 18, 150-171. [CrossRef]

18. Hellberg, A.S.; Hedström, K. The Story of the Sixth Myth of Open Data and Open Government. Transform. Gov. People Process Policy 2015, 9, 35-51. [CrossRef]

19. Ng, A.K.Y. The Evolution and Research Trends of Port Geography. Prof. Geogr. 2013, 65, 65-86. [CrossRef]

20. Ducruet, C.; Zaidi, F. Maritime Constellations: A Complex Network Approach to Shipping and Ports. Marit. Policy Manag. 2012, 39, 151-168. [CrossRef] 
21. Ng, A.K.Y.; Ducruet, C.; Jacobs, W.; Monios, J.; Notteboom, T.; Rodrigue, J.-P.; Slack, B.; Tam, K.; Wilmsmeier, G. Port Geography at the Crossroads with Human Geography: Between Flows and Spaces. J. Transp. Geogr. 2014, 41, 84-96. [CrossRef]

22. Hämäläinen, E.; Inkinen, T. How to Generate Economic and Sustainability Reports from Big Data? Qualifications of Process Industry. Processes 2017, 5, 64. [CrossRef]

23. Chatfield, A.T.; Reddick, C.G. A Longitudinal Cross-Sector Analysis of Open Data Portal Service Capability: The Case of Australian Local Governments. Gov. Inf. Q. 2017, 34, 231-243. [CrossRef]

24. Inkinen, T. Does Size or Geography Matter? Empirical Analysis of Finnish Local Government Services on the Internet. In Comparative E-Government: An Examination of E-Government Adoption Across Countries. Integrated Series in Information Systems; Reddick, C., Ed.; Springer: New York, NY, USA, 2010; Volume 25, pp. 615-637.

25. Inkinen, T. Examining Public Sector Electronic Services in Finland. In Public Sector Transformation through E-Government: Experiences from Europe and North America; Weerakkody, V., Reddick, C.G., Eds.; Routledge: London, UK, 2012; pp. 91-106.

26. Dahlander, L.; Gann, D.M. How Open is Innovation? Res. Policy 2010, 39, 699-709. [CrossRef]

27. European Commission. Digital Transformation Scoreboard 2017. 2017. Available online: https://ec.europa. eu/growth/content/digital-transformation-scoreboard-2017_en (accessed on 25 February 2018).

28. Elmquist, M.; Fredberg, T.T.; Ollila, S. Exploring the Field of Open Innovation. Eur. J. Innov. Manag. 2009, 12, 326-345. [CrossRef]

29. Inkinen, T.; Hämäläinen, E. The Development of Sea Transported International Trade Value of Finland 2002-2016. In Proceedings of the 23rd International Conference of Hong Kong Society for Transportation Studies, Hong Kong, China, 8-10 December 2018; pp. 407-414, ISBN 978-988-15814-7-1.

30. Finnish Transport Infrastructure Agency. Foreign Sea Transport Statistics. 2018. Available online: https: //www.liikennevirasto.fi/tilastot/vesiliikennetilastot/ulkomaan-meriliikenne\#.W6DCEvloSpo (accessed on 25 February 2019).

31. Jaakola, A.; Kekkonen, H.; Lahti, T.; Manninen, A. Open Data, Open Cities: Experiences from the Helsinki Metropolitan Area. Case Helsinki Region Infoshare www.hri.fi. Stat. J. IAOS 2015, 31, 117-122. [CrossRef]

32. Witt, U. What Kind of Innovations Do We Need to Secure Our Future? J. Open Innov. Technol. Mark. Complex. 2016, 2, 17. [CrossRef]

33. Rodrigue, J.-P.; Comtois, C.; Slack, B. The Geography of Transport Systems, 2nd ed.; Routledge: London, UK, 2009.

34. Svaetichin, I.; Inkinen, T. Port Waste Management in the Baltic Sea Area: A Four Port Study on the Legal Requirements, Processes and Collaboration. Sustainability 2017, 9, 699. [CrossRef]

35. Makkonen, T.; Inkinen, T. Sectoral and technological systems of environmental innovation: The case of marine scrubber systems. J. Clean. Prod. 2018, 200, 110-121. [CrossRef]

36. Jinhyo, J.Y.; EuiSeob, J.; YoungKyu, L.; KyungHun, K. The Effect of Open Innovation on Technology Value and Technology Transfer: A Comparative Analysis of the Automotive, Robotics, and Aviation Industries of Korea. Sustainability 2018, 10, 2459. [CrossRef]

37. Bargh, M.S.; Choenni, S.; Meijer, R. Meeting open data halfway: On semi-open data paradigm. In Proceedings of the 9th International Conference on Theory and Practice of Electronic Governance, Montevideo, Uruguay, 1-3 March 2016; ACM: New York, NY, USA, 2016; pp. 199-206.

(C) 2019 by the authors. Licensee MDPI, Basel, Switzerland. This article is an open access article distributed under the terms and conditions of the Creative Commons Attribution (CC BY) license (http://creativecommons.org/licenses/by/4.0/). 